SERVIÇO DO PROF. CELESTINO BOURROUL

\title{
CASO AUTÓCTONE DE MALÁRIA EM SÃo PAULO \\ (CAPITAL)
}

\section{DR. GASTÃO ROSENFELD}

Chefe do Laboratorio
DR. HERSCHEL SCHECHTMANN

H̀a cinco anos observámos o caso que ora apresentamos. Publicamo-lo sómente agora, pois não tinhamos, naquela ocasião conhecimento do alcance do assunto.

O interesse do caso consiste em ser São Paulo tida por muitos como cidade com anofelismo sem malaria.

O, anofelismo em São Paulo já está bem comprovado, pois, nos arredores da cidade já foram encontradas varias especies de anofelineos transmissores da malária, tendo mesmo GaLVÃo \& LANE (1937) e Galvão (1938) infetado experimentalmente com Plasmodium vivax alguns exemplares de Anopheles albitarsis e Anopheles strodei capturados num dos bairros da Capital, VARGAS (1939) já emitiu a opinião de que os arredores de S. Paulo não eram propriamente zona de anofelismo sem malária como provavam os casos esporadicos de malária, observados.

A ausencia de malária autóctone em São Paulo, apesar da existencia de anofelíneos transmissores da molestia, é curiosa por dois fatos: em primeiro lugar o de existir na Capital numerosos maleitosos que vêm em busca de tratamento ou que nela residindo adoeceram em outras zonas do Estado; em segundo lugar o de ser essa cidade contigua á de Santo Amaro (atualmente incorporada ao municipio de São Paulo), onde a malária é endemica. Galvão (1940) fez referencia ao surto de malária que atingiu os arredores desta ultima localidade nesse ano. Em 1941 Santo Amaro foi duramente atingida pelo surto de recrudecimento da moléstia, do mesmo modo que todo o Estado, tendo um de nós (Rosenfeld) comprovado nesses dois ultimos anos numerosos casos de malária (Plasmodium vivax e falciparum) provenientes dessa localidade e arredores. Muito recentemente Galvão e GrIeco (1941) comunicaram o achado do A. dárlingi encontrado naturalmente infectado nessa zona, e dado identico foi comunicado por FonseCa \& BRAGança \& Covelili \& Zwicker (1941).

A razão de ser desse privilegio da cidade de São Paulo é desconhecida e é assunto fora de nosso alcance. Com a apresentação

(*) Comunicação feita a secção de Higiene, Molestias Tropicaes e Infeciosas da Associação Paulista de Medicina em 4-10-1941. 
de um caso de malária certamente autóctone queremos contribuir para a documentação de futuros estudos que se proponham resolver o assunto.

Já foram publicados alguns casos (considerando sómente a cidade de São Paulo), muito provavelmente autóctones, mas a todos eles foi feita a critica de deixar uma duvida, pois, tratava-se de individuos que haviam estado anteriormente em zonas onde a malária é endêmica. Faremos uma breve revisão desses casos: os dois primeiros tinham Plasmodium vivax e o ultimo Plasmodium falciparum (esquizontes).

O primeiro desses casos foi o de Prado \& Godinho (1935). Tratava-se de um individuo que ao adoecer residia numa olaria á margem do rio Pirajussára, no bairro de Butantan. Dezoito mezes antes estivera em Marilia e Torrinha, onde ha malária.

O segundo caso citado por VARGAs (1939) era o de um operario que adoeceu no bairro de Pinheiros.

O terceiro caso, relatado por Mello (1941), é o de um individuo que nesse ano adoeceu em plena época malarigena, no bairro da Villa Clementino. Um ano antes estivera em Santos mas ficára num bairro em que casos de malária são excepcionais (Praia do Gonzaga).

\section{CASO}

A. S. - 38 anos, polonesa, tendo vindo ao Brasil em 1930 Era enfermeira na Polonia e aqui é costureira.

Aos "10 anos teve escarlatina sem complicações. Trabalhou como enfermeira em hospitais, durante a epidemia de tifo exantematico na Polonia em 1917, onde, contraíu a molestia tendo tido complicações pul-monares (pneumonia) (sic). Nunca teve febre suspeita de malária nem molestia febril de diagnostico duvidoso. Natural de Varsovia, sempre residiu lá, região indene de malária.

Desde que chegou ao Brasil, reside no bairro do Bom Retiro, nunca. tendo se afastado da Capital, nem mesmo a passeio. Ao ficar doente residia á rua Conego Martins, junto á linha da Estrada de Ferro Sorocabana e da São Paulo Railway e a 800 metros em linha reta da varzea das margens do rio Tieté.

Em Abril de 1936 adoeceu com acessos febris atingindo $40^{\circ}$, cada dois dias, precedidos de calafrios, acompanhados de cefaléa e vomitos intensos, o baço não era palpavel e emagreceu 8 quilos em 15 dias.

Apesar do quadro clinico não foi lembrada a hipotese de malária devido ao fato da doente não ter saido da Capital.

Foi feita hemocultura e pesquiza de púz na urina, sendo negativos ambos os exames. Ao ser feito o hemograma em 13/4/1936, foram encontrados numerosos esquizontes de Plasmodium vivax.

Foi feito tratamento com quinina e azul de metileno (Paludan), ficando clinicamente curada.

Em Outubro do mesmo ano, 6 meses depois, recidiva da molestia com esplenomegalia, revelando o exame, em 29/10/1936, numerosos esquizontes e raras formas amiboides de Plasmodium vivax.

Tratada com Plasmoquina, azul de metileno por via endovenosa e radioterapia (4 aplicaçôes) sobre o baço, a conselho de outro clinico, ficou curada não tendo tido nada mais até a presente data (Julho de 1941). 


\section{COMENTARIOS}

Não ha duvida que o caso ora relatado contraíu a malária nesta Capital. Cabem duas hipoteses quanto ao modo da infecção; ou a doente foi picada por mosquito infectado que véio num trem ou, o anofele provinha da varzea do rio Tiété. A primeira hipotese nos parece a mais provavel pois a residencia distava cerca de 200 metros da estrada de ferro pela qual trafegavam trens que vinham de regiões paludossas. A segunda hipotese si bem que menos provavel é acceitavel pois anofelineos das margens do Tiété, podem ter se infectado em doente vindo de alguma zona do Estado afim de se: tratar na Capital.

\section{RESUMO}

Os A. A., depois de alguns comentarios sobre o assumpto, fazem um breve resumo dos tres casos anteriormente publicados e apresentam o caso de uma doente qúe nunca tendo estado em região padudosa contraiu a malária (Plasmodium vivax) na Capitāl de São. Paulo.

\section{BIBLIOGRAFIA}

Fonseca, F. DA \& Bragança, U. \& Covelli, E. \& Zwicker, R. - 1941 Verificação da infeç̧ão natural do $A$. darlingi no municipio de S. Paulo, Comunicação á sessão de Higiene, Molestias Tropicais e Infecciosas da Associaçãa Paulista de Medicina em 15, Julho, 1941.

Galvão, A. L. Ayroza \& LÁNe, J. - 1937 - Notas sobre os Nyssorhyncus de São Paulo. IV: Sobre a infecção experimental do 'Anopheles albitarsis e $A$. strodei da cidade de S. Paulo, pelo Plasmodium viváx. Fol. clin. biol." $9(3): 65-69$, jun.

Galvão, A. L. AyrozA - 1938 - Sobre a infecção experimental do Anopheles strodei pelo Plasmodium vivax, Rev. biol. hyg. 9(2):133-134, dez.

Galvão, A. L. Ayroza - 1940 - O surto de malaria nas proximidades da repreza do Rio Grande nas imediações da cidade de São Paulo e o Anopheles darlingi Root, 1926, Rev. biol. hyg. 10(2) :164-169, jun.

Galvão, A. L. Ayroza \& GRIEco, F. - 1941 - Infecção natural do Anopheles (M.) darlingi pelos parasitas da malaria, nos arredores de S: Paulo, Comunicação á secção de Higiene, Molestias Tropicaes e Infecciosàs da Associação Paulista de Medicina em 4, Junho, 1941.

Mello, H. K. DE - 1941 - Sobre um caso de malaria observado na Capital de S. Paulo, Rev. clin. de S. Paulo, 9(5):168-169, maio.

PrAdo, A. \& Godrnho, R. - $1935^{\circ}$ - Provavel caso autoctone de impaludismo registado. em São Paulo, Ann. paul. med. cir. 29(4) : 295-297.

VARGAS, A. - 1939 - Alguns aspectos epidemiologicos da malaria no planalto: de São Paulo,. Ann. paul. med. cir. 38(6):445-453. 


\section{IISSIIUTO DE FISIOTERAPII VITOFLWX O MAIS MODERNO DE SÃO PAULO}

Diretor clinico:

Dr. Manoel I. Romeiro DIRETOR TECNICO

Dr. Albert Kestenberg da Faculdade de Medicina de Paris

CORRENTES DE BAIXA FREQUENCIA VITOFLUX ONDAS CURTAS - DIATERMIA

FEBRE ARTIFICIAL - RAIOS ULTRA-VIOLETAS

BANHO INTESTINAL ASPIRATIVO

RAIOS INFRA-VERMELHOS

CORRENTE GALVA.N. E FARAD. - IONISAÇÃO

TELEFONE $4-7286$

DAS 2 ÁS 6 E

HORA MARCADA

RUA XAVIER DE TOLEDO, $98-4 .^{\circ}$ and. - sala 46 S ÃO P A U L O 